Article

\title{
Post-Occupancy Evaluation Data Support for Planning and Management of Building Maintenance Plans
}

\author{
Nelson Bento Pereira, Rui Calejo Rodrigues and Patrícia Fernandes Rocha * \\ Center for Buildings in Use Studies, Faculty of Engineering, University of Porto, Porto 4200-465, Portugal; \\ nbp@fe.up.pt (N.B.P.); calejo@fe.up.pt (R.C.R.) \\ * Correspondence: patfrocha@fe.up.pt; Tel.: +351-220-413-799
}

Academic Editor: David Arditi

Received: 19 July 2016; Accepted: 17 October 2016; Published: 21 October 2016

\begin{abstract}
The purpose of this paper is to propose a post-occupancy evaluation (POE) method focused on building maintenance and then to test it on two different sets of residential buildings. The paper's three main goals are: to obtain useful data for optimizing the buildings' maintenance plans; to search for any correlation between the occupants' characteristics and their expectations toward the building; to study the occupants' willingness to pay for maintenance procedures, as well as its correlation with the occupants' perception of the elements source of maintenance (ESM). The proposed POE method for building maintenance performance evaluation (BMPE) consists of six main stages, focusing on the occupants' opinions and their correlation with the facility manager's. The observed case studies allowed for a preliminary validation of the POE method for BMPE. Results generically endorsed the method as a valuable tool for the rapprochement between facility management and the building's end-users. Such findings could allow facility managers to develop more efficient maintenance plans focusing on the occupants' real needs and expectations, raising occupant satisfaction levels and contributing to the building's general performance.
\end{abstract}

Keywords: post-occupancy evaluation; facility management; building maintenance; maintenance plan; element source of maintenance; occupant exigency index; willingness to pay

\section{Introduction}

A building's lifecycle can be divided into five main stages: planning, design, construction, use and end of life [1], each with its own evaluation process. Post-occupancy evaluation (POE) aims exclusively at the use stage of the building's lifecycle, and has been defined as the examination of the effectiveness for human users of the occupied built environment [2]. Unlike other kinds of building evaluations, which focus mainly on aesthetical factors, constructed systems or materials performance, POE concentrates on the evaluation of the building in order to juxtapose it to the occupants' comfort and needs [3].

Spanning through an array of fields and professions [4], POE was first introduced in the 1960s, and was first applied to large governmental services buildings [5]. Throughout the 1980s, POE was subject to a considerable advancement in theory, method and strategy, becoming an important tool for facility management for all the additional input it provided to designers and facility managers alike [6]. POE focuses on the occupants' assessment as a tool for the diagnosis of existing problems in the building's performance, as well as benchmarking for future reference [5]. Most of the POE studies applied to residential buildings focused on energy use, indoor space distribution, occupant behavior, and overall satisfaction [7]. Lately, POE has also been used as a reliable method to investigate thermal comfort in buildings [8]. According to Zimring and Reizenstein [2], there are three dimensions to 
POE: the degree of specificity for the collected data, the amplitude of scope, and the time window for the evaluation.

Even though maintenance is essential for the adequate performance of buildings, and POE is a form of evaluation which highlights the occupants' needs, there was yet no formal approach to the incorporation of POE data as a tool for maintenance planning or management. The question emerges for POE data to support the planning, monitoring and optimization of building maintenance scheduling and operations, which is why this paper aims to originally propose an approach methodology.

Building maintenance is defined by Seely [9] as "work undertaken in order to keep, restore or improve every part of a building, its services and surrounds, to a currently accepted standard, and to sustain the utility and value of the building", while ISO 6707-1 [10] defines it as the combination of all technical and associated administrative actions during the service life to retain a building in a state in which it can perform its required functions.

Even though each particular building should be subject to its own maintenance plan, tailored to the building's needs in terms of its elements source of maintenance (ESM), as defined by Rodrigues and Rocha [11], general practice tends to privilege the production of generic plans to be executed in several similar buildings. This sort of practice makes sense from the point of view of the facility manager, for its pragmatism and general efficiency.

However, in reality, similar buildings are occupied by different sorts of occupants, with different sorts of needs and expectations. It seems safe to expect that the occupants' age, gender or social background will influence the way they experience similar buildings. This raises the issue to consider these different needs and expectations for the building's performance in maintenance planning.

POE may therefore constitute a valuable tool to allow facility managers to assess potential gaps between the building's performance and the occupants' needs and expectations, and consequently to adjust the building's maintenance operations and scheduling to better suit its occupants' needs.

\section{Methodology}

The proposed POE method for building maintenance performance evaluation (BMPE) consists of six main stages, as presented in Figure 1. The process begins with a comprehensive consultation of the building's designs, as well as its maintenance plan, which provides the basis for the selection of the ESMs to be considered throughout the evaluation process. This is followed by a complete inspection of the building to assess its compliance with the existing designs on location. Enquiries may then be made and presented to the occupants, followed by the data analysis and management. The last stage consists of using all the occupant evaluation data in order to produce new maintenance sheets and/or improve existing ones.

The process is initiated with the consultation of the building's designs. This provides the technician with the necessary knowledge of the main architectural, structural and functional aspects of the building. Whenever the designs are inexistent or considered incomplete, it is mandatory to fill the gaps via on-site inspections, in order to advance to the next stage of evaluation. The building's maintenance plan must also be studied in this preliminary stage. A comprehensive knowledge of the maintenance's scheduling and procedures will allow for a more focused evaluation.

The second stage is the designation of the ESMs. This procedure requires the careful consideration of other matters besides the building's physical characteristics alone, such as the amount of time available for the evaluation and the occupants' low sensibility to some of the building's ESM's. This does not necessarily mean these elements cannot be evaluated. It means, however, that the resulting data may be decontextualized.

The third stage consists of on-site inspections. Being as the ESMs have already been designated, the inspections ought to focus on those. It is important that the technician conducts this inspection being mindful of the occupants' view. The inspection allows for the conduction of a complete photographic report to support the next stages. The facility manager must accompany the technician at the inspections in order to provide valuable data about the building's maintenance history. 


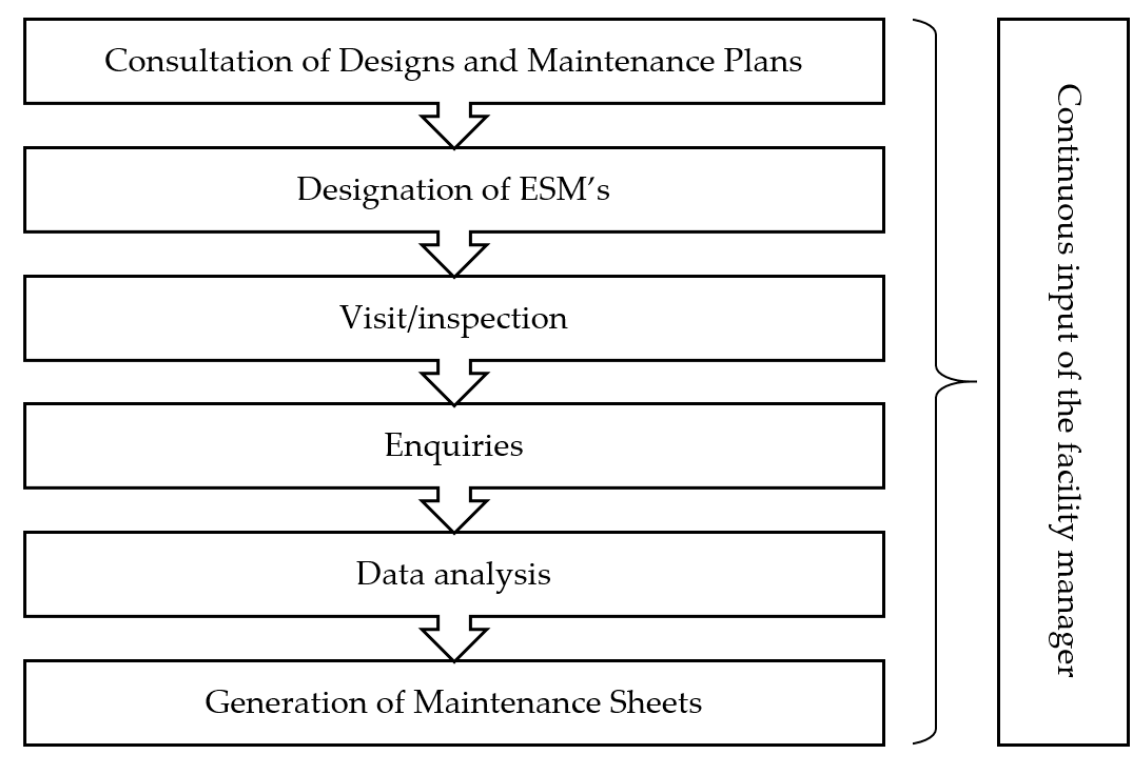

Figure 1. Process stages.

The fourth stage, crafting the enquiries, is the most crucial for the success of the evaluation. It is important to use a simple and non-technical communication, allowing the answers to be as objective and succinct as possible. In some cases, it is important to divide the information for one maintenance procedure into several simple questions, with two main objectives: to simplify the understanding of the question and to enable an unbiased opinion. In the data analysis stage these different responses may be combined to provide useful data for maintenance evaluation and planning. Best practices advise having multiple choice questions with five response options [12]. This allows the occupant to clearly distinguish the extremes and middle of the response scale. The questionnaire must also aim to allow the assessment of correlations between the occupants' characteristics and their perceptions of the building. This demands the inclusion of questions regarding the occupants' age, gender, period of stay, relative location on the building, or the ownership relation to the property. Finally, the technician must carefully consider the best method for conducting the enquiries to the occupants. This approach might be by mail or interview depending on the depth of the questionnaire and the characteristics of the occupants.

Figure 2 presents a sample of the questionnaire employed in the case studies to be presented later.

Once the enquiry data is gathered, it must be processed and analyzed. The combination and statistical handling of the raw responses will deliver more valuable data.

The last stage of the process involves the profound examination of the processed data in order to establish the recommendations for the building's maintenance. The data allows the technician and facility manager to evaluate the pros and cons of the maintenance practices and assess where to focus future efforts for maximum return in terms of end-user satisfaction. There is also a pressing opportunity to assess cost-efficiency in the various maintenance procedures, by assessing the correlation between spending on and increase in occupant satisfaction.

The final results are organized in technical maintenance sheets, as shown in Figure 3. These sheets will contain: the addressed ESM, the period of evaluation, the applied evaluation methods, a brief presentation of results and finally, a set of advice to be considered by the facility manager on the planning and improvement of the building's maintenance plan.

The continuous accompaniment of the whole process by the facility manager is key to its success. The facility manager is always the best database of knowledge regarding the building and its maintenance history. The manager's intervention will allow for frequent and constant adjustments to the several stages of the process. 


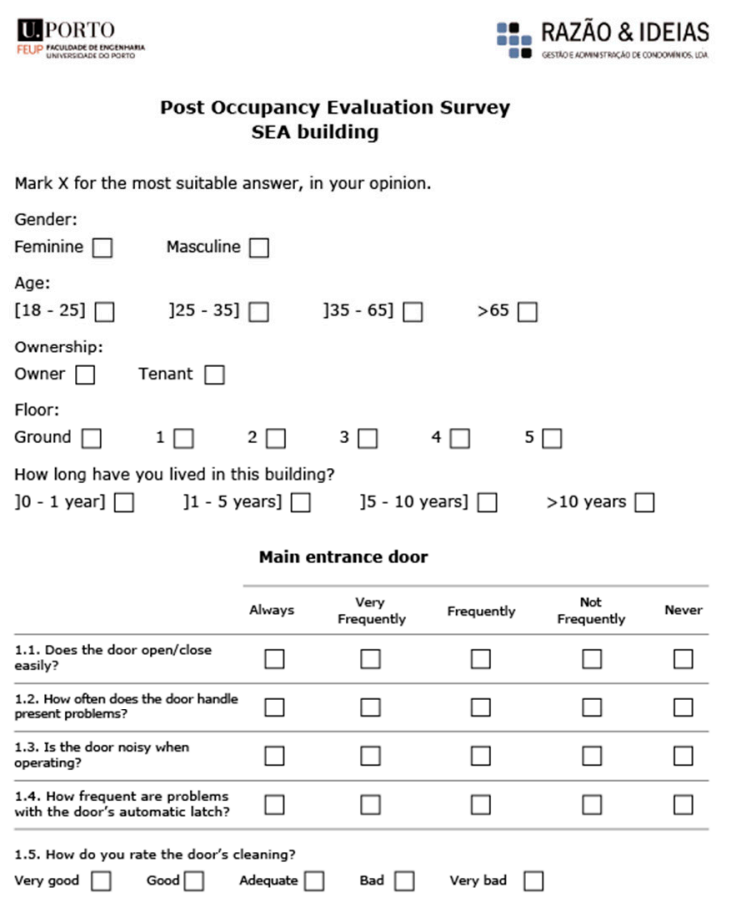

\section{-7e}

\section{U.PORTO}

H. RAZÃO \& IDEIAS

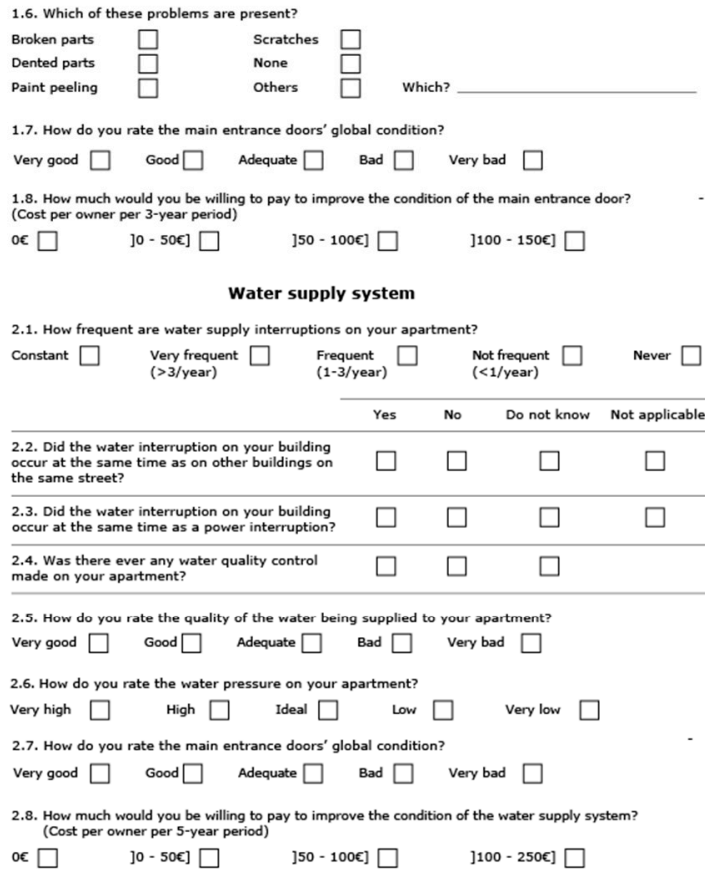

Ter

Figure 2. Questionnaire sample. The first questions establish the occupant's characteristics. The following questions regard the multiple ESMs to be evaluated. 


\title{
Post-occupancy evaluation data support for planning and management of building maintenance plans
}

\author{
Building: SEA \\ Element source of maintenance: \\ Garage \\ Evaluation period: \\ march to may 2016
}

Data collection techniques:

Physical parameters measurement

Photographic survey

Visual observation

Group meetings

Global score:

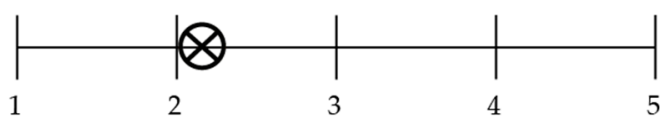

Results summary:

The results of APO showed that users are generally dissatisfied with the state of the garage. The more serious problems pointed out by the occupants and confirmed by the facility manager were related to severe water

infiltrations and some cases of walls and pavements cracking.

Users also complained about the fading markings on the garage floor.

Globally, the ESM was attributed a global score of 2,18.

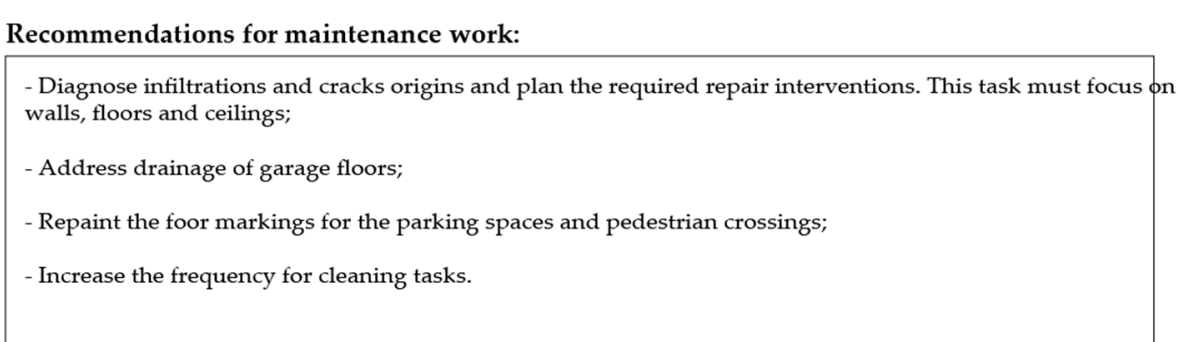

Figure 3. Maintenance sheet example.

\section{Case Overview}

The proposed POE method for BMPE will be applied to two sets of residential buildings, both in the city of Porto, Portugal. All of the buildings are condominiums, constituted under common ownership. The aim was to select buildings with similarities regarding architecture, constructive solutions and urban context, as well as differences in the characteristics of the occupants.

Both sets are constituted by multistoried buildings, located in a suburban city outside Porto, and were constructed in 2001, each with a total of about 200 apartments and between five to 10 shops on the ground floor, an underground shared garage, and external recreational areas. Constructive solutions are typical of the date: concrete structure, brick masonry walls, and flat 
roofs. Both sets of buildings were subject to a major restoration of roofing and facade in 2014, as they both evidenced severe waterproofing anomalies. Both sets house about 500 occupants each.

The occupancy patterns are deeply divergent between both sets of buildings, which provides an ideal set of circumstances to evaluate the influence of the occupant's profile in its use and perception of the built environment. The first set, consisting of nine buildings, to be designated from here forward as UNI, is located next to a university campus. Its location leads to a very specific occupancy pattern, as the buildings are mostly occupied by college student tenants. The second set, consisting of 11 buildings, to be designated as SEA, is located on the seaside, and is mostly occupied by traditional families. The characteristics of the buildings' occupants are further detailed in Figure 4, with regard to three main features: whether the occupant owns or leases the apartment, the occupant's age and the occupant's time of occupancy in the set apartment.

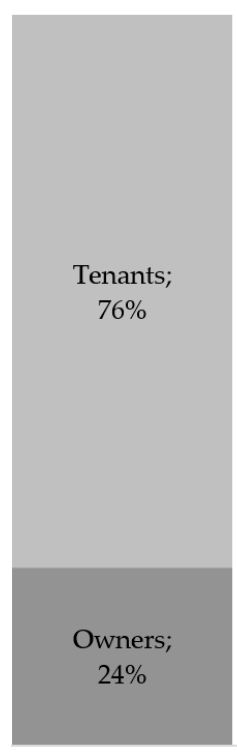

UNI

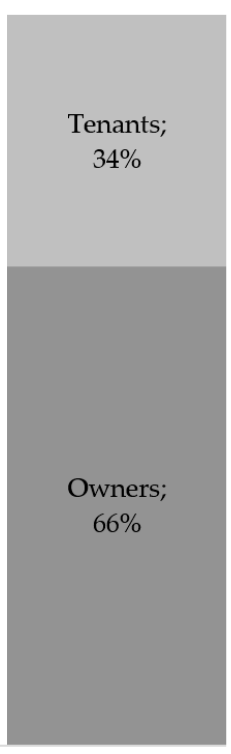

SEA

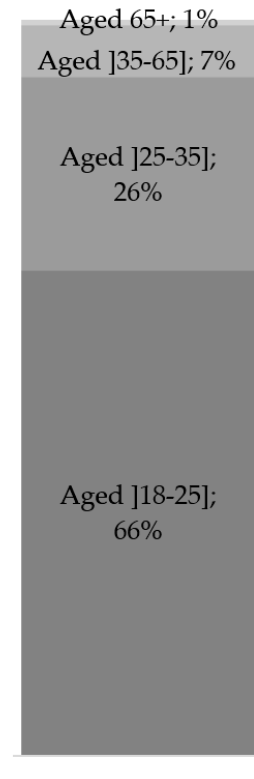

UNI

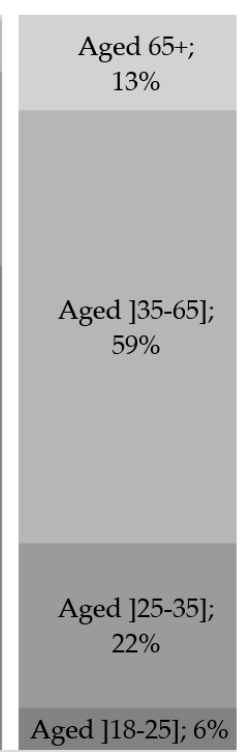

SEA

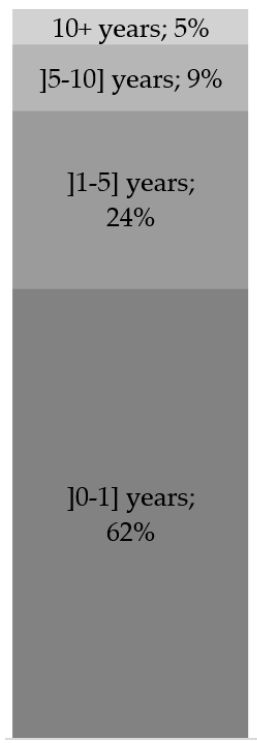

UNI

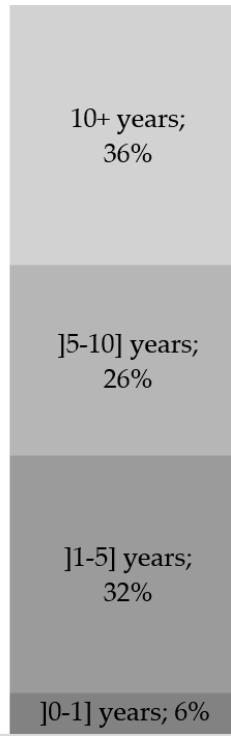

SEA

(a)

(b)

(c)

Figure 4. The two sets of buildings were selected in order to provide two samples of occupants with utterly diverging distributions of three essential features: (a) Ownership; (b) Occupant's age; (c) Time of occupancy.

The analysis of the occupants' characteristics provides us with two typical profiles. The UNI typical occupant is a student tenant, under 25 years old, who uses the building for less than five years before moving. The SEA typical occupant owns the apartment, is aged from 25 to 65 years, and uses the building for four to six years before moving.

\section{Results}

\subsection{Summary of Responses}

The first phase of the survey was conducted by means of a questionnaire sent via e-mail to all the owners and tenants in the buildings. This phase provided around one-fourth of the total responses. The second phase was based on telephone calls to the remaining owners and tenants. The telephone phase provided around one half of the total answers. The third and last phase consisted of personal interviews made at the building's locations, accounting for around one-fourth of the total amount of answers. 
Even though both sets of buildings house about 500 occupants each, only 377 occupants were contacted in UNI and 448 in SEA, with 144 responses in UNI and 256 responses in SEA. The response success rate was $38 \%$ in UNI and $57 \%$ in SEA.

This preliminary survey aimed to validate the method, and hence the survey focused on a limited set of the buildings' elements, namely the entrance doors, the water supply system, the facade walls, the interior hallways and the shared garage.

The occupants' responses concerning the entrance doors were homogeneous with regard to cleaning parameters, with a $10 \%$ coefficient of variation $(\mathrm{CV})$, but very diverse in regard to other maintenance parameters (between $16 \%$ to $27 \% \mathrm{CV}$ ), which was expected due to the fact that there are nine doors in UNI and 11 doors in SEA. This diversity in the data indicated the future need to include the specification of the entrance door on the enquiries. The global score for entrance doors was, on both buildings, between acceptable and good. The most common problems as perceived by UNI occupants were: paint peeling, scratches and broken parts. Some emphasis was noticeable regarding door handle anomalies. SEA occupants accentuated dents, broken parts, scratches and security failures.

The occupants' responses indicated general satisfaction regarding the water supply system, with a global score very close to good. Water supply failures were, from the occupants' view, infrequent. Regarding the water quality, occupants were largely pleased, even though there was a general lack of knowledge about the existence or frequency of chemical and biological control. Opinions about water pressure were more diverse. The global evaluation was close to ideal, but some considerable discrepancies were reported for UNI, which may be caused by anomalies in water pressure control, but may also be the result of differences in time of use, as pressure is expected to reduce during peak usage hours.

The survey concerning the buildings' facades proved very interesting. About $48 \%$ of the UNI occupants that had experienced water infiltration anomalies before the exterior repair intervention claimed the water infiltration persisted. The percentage of this perception was raised to $73 \%$ in SEA occupants. However, a simple measurement of the moisture level on the interior walls showed that only $6 \%$ of the anomalies endured in UNI and $14 \%$ in SEA, which proved that most of the occupants' opinions were unfounded, and were merely originated by the persisting manifestations of the former anomaly on the interior walls, which were never repaired. With regard to the facade cleanliness, UNI occupants were unable to identify complaints, and SEA occupants reported only the existence of surface dust. Still, in both buildings, the score for the facade's cleanliness was set between adequate and good. Global scores for the facades were good for UNI but only adequate for SEA, which is probably related to the occupants' perception about the inefficacy of the exterior repair works.

Regarding the interior communal spaces, occupants on both buildings were generally pleased in terms of cleanliness and lighting timing, color and dispersion, attributing a global score of good.

Both buildings' data established the shared garage space as the main focus of complaints. Occupants in both buildings identified oil stains, dust and water infiltrations as the main annoyances. The score for the garage's cleanliness was adequate for both buildings, but the global score was adequate for UNI and bad for SEA. As for garage lighting, occupants of both buildings claimed to be generally satisfied with regard to the light's intensity, color and timing. There were somewhat big discrepancies in occupants' responses about faulty lamps ( $24 \%$ CV for UNI and $16 \%$ CV for SEA), which may be related to their attention level when using the spaces.

Occupants in both buildings classified the proneness for issues in the opening and closing of the garage door as average. For the UNI building, occupants also reported dented parts and security issues. SEA occupants reported paint peeling, scratches, motor unit faults and security issues. Regarding the amount of time each automatic door spent open, the standard deviation for occupants' responses was high ( $28 \%$ CV for UNI and $21 \%$ CV for SEA), with a reduced amount of occupants showing concerns about the effect on the building's security. In regard to security issues, it was interesting to observe that only a small amount of the occupants stated it as a concern of theirs, specifically $9 \%$ of UNI occupants and $14 \%$ of SEA occupants. However, the ones that did present this concern were very firm in this 
statement and seemed really apprehensive. It was also observable that this concern was more common on older occupants and none of the tenants presented security concerns, which indicates it may be a concern only for owners.

\subsection{Conditioned Analysis}

The gathered data was combined with the occupants' characteristics in order to assess the existence of correspondences between the occupants' traits and their tendency toward particular opinions. An evaluation index was created in order to make sense of the collected data. Therefore, the occupant exigency index (OEI) aims to express the degree of exigency exposed by the occupant's assessments and is defined by the following equation:

$$
\text { OEI }=1-\text { (Average grade/Total number of response options), }
$$

in which the average grade is the arithmetic average of the grades attributed by the selected group of occupants, arranged numerically from zero to four, with zero expressing the worst grade, and the total number of response options being, in the present case study, five. This index is consequently only applicable when all the questions in the questionnaire have the same consistent number of response options.

The OEI was applied to five different occupant characteristics: age, gender, ownership status, apartment floor, and time of occupancy. No concrete tendencies in the degree of exigency were found for two of these characteristics, namely gender and apartment floor. On the other hand, the results showed clear trends for ownership status, occupant's age, and time of occupancy, as shown in Figure 5.

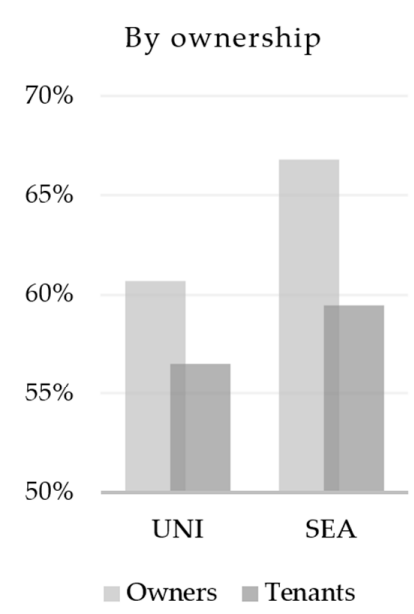

(a)
By occupant's age

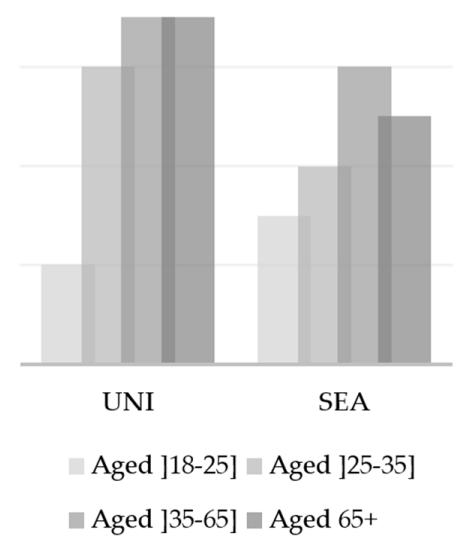

(b)

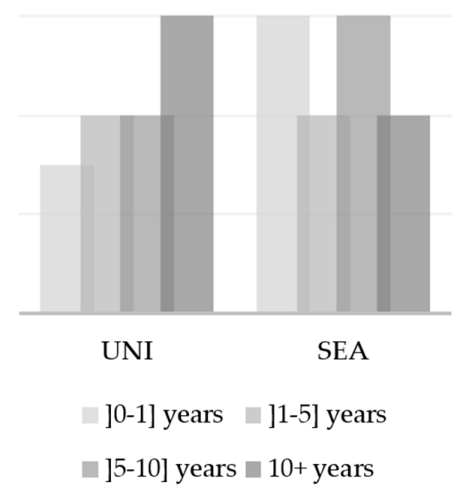

(c)

Figure 5. Data for the OEI: (a) By ownership; (b) By occupant's age; (c) By time of occupancy.

Results show owners (61/67\% OEI) were clearly more demanding than tenants $(57 / 59 \%$ OEI). Older occupants were also more demanding than younger ones.

\subsection{Willingness to Pay}

In Portugal, the financing of maintenance costs in condominiums is achieved through the setting of an annual budget for this purpose. This budget is pre-approved by the common owners and usually includes only current expenditures, with supplementary maintenance costs being set in the midst of budget execution, whenever necessities arise. It was therefore considered important to include one question in each questionnaire chapter to address the occupants' willingness to pay for future maintenance procedures in said ESM. 
Results largely revealed tenants displayed no willingness to pay, as they considered the investment should be the owner's responsibility. Regarding owner occupants, responses generally indicated occupants were seldom willing to pay any amount, even when they previously stated the ESM in question needed improving.

No correspondence was established between the score awarded to each ESM and the occupants' willingness to pay for its maintenance procedures. There was, however, a generally higher willingness to pay for ESMs with lower maintenance costs, such as the entrance door or the garage's lighting.

The data analysis allowed for the characterization of significant occupant profiles based on the occupants' personal features and their pattern of approach to the building's maintenance needs. Three significant occupant profiles were established in the present case studies, as shown in Figure 6.

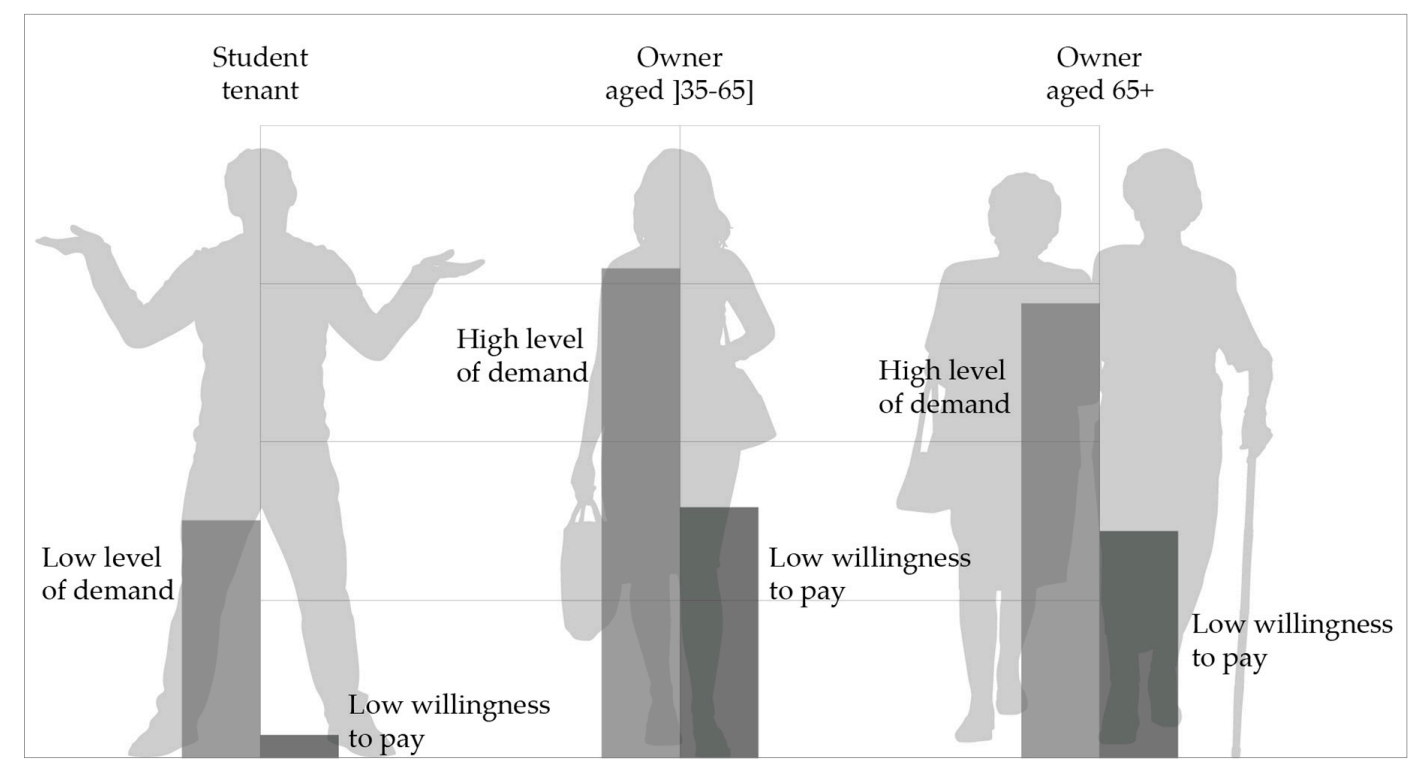

Figure 6. Significant occupant profiles.

\subsection{Occupant Perception vs. Facility Manager Perception}

An interview with the facility manager was conducted during the stage of surveying, to record his opinions on the buildings and also to assess his expectations regarding the users' opinions. The aim was to measure discrepancies between the three different sets of opinions: the facility manager's evaluation, the occupants' evaluation and the facility manager's expectation for the occupants' opinions.

Results indicated the existence of a discernable gap between the facility manager's perception and the occupants', as presented in the following figures.

Figure 7 presents the main results of the interview for UNI and Figure 8 presents the main results of the interview for SEA.

The facility manager's main concerns were the garage's automatic doors in UNI and the main entrance doors and facade walls in SEA. Occupants, however, contradicted this perception. UNI occupants rated the garage's automatic doors as above adequate and the SEA occupants rated the main entrance doors and the facade walls as above adequate.

This gap emphasizes how the close proximity to the building's everyday faults may exacerbate the perception of the condition of some ESMs and impair the facility manager's general judgment about the building's maintenance as a whole. 


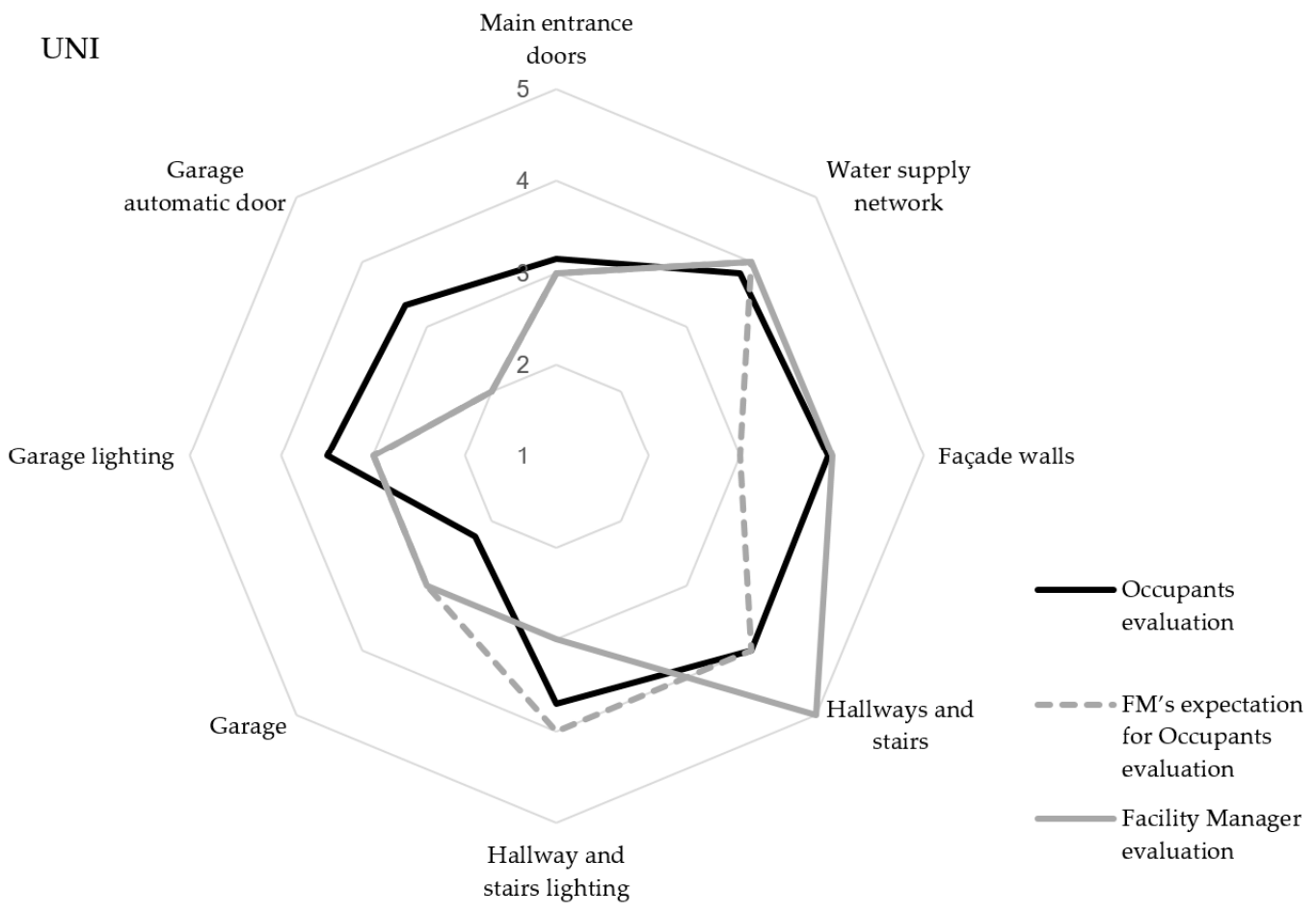

Figure 7. Occupant perception vs. facility manager perception-UNI.

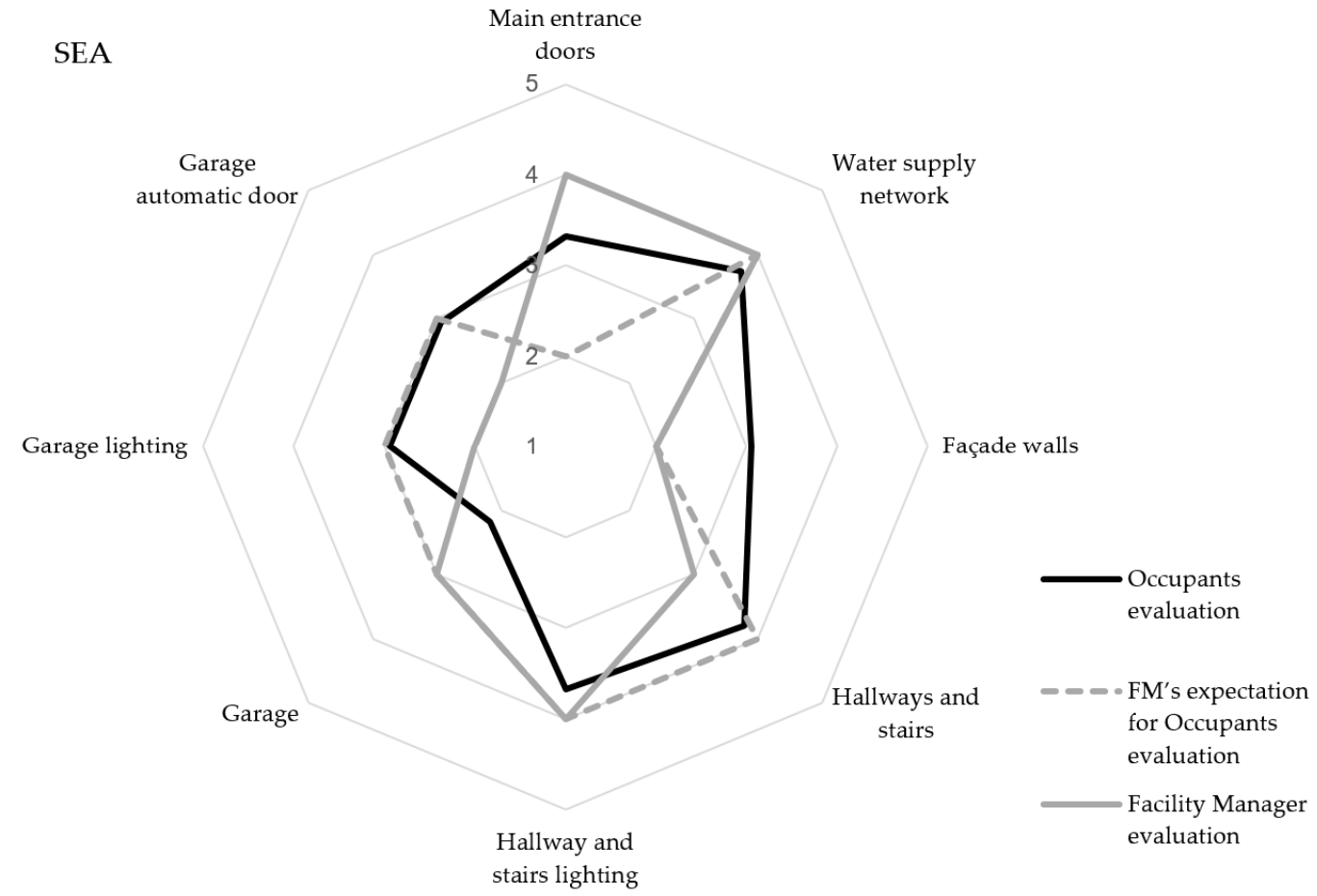

Figure 8. Occupant perception vs. facility manager perception-SEA.

\section{Conclusions/Further Research}

The present case studies allowed for a preliminary validation of the POE method for BMPE. Results generally endorsed the method as a valuable tool for the rapprochement between facility management and the building's end-users. 
The inclusion of specific faults on the questionnaire to the occupants provided useful data to support concrete recommendations for maintenance procedures and scheduling. For example, regarding the main entrance doors, occupants complained specifically about dented and broken parts, which may be corrected by dedicated procedures.

The data also provides information about what particular faults most impact the occupants, which might prove useful to support broader strategic decisions regarding the building's long-term maintenance decisions and future investments. For example, occupants in both buildings showed deep concerns about security issues whenever a fault in the garage's automatic doors motors forced the doors to remain open throughout the night, which may indicate occupants would be receptive to a proposal for the installation of improved and durable new motors, or the acquisition of an alternative motor to be used during repair periods.

Evaluating two separate sets of buildings with different features of occupation provided the chance to examine the differences and similarities of the occupants' opinions. The case studies also provided data supporting the existence of a pattern of correlation between the occupants' characteristics and their degrees of exigency and willingness to invest. Patterns of behavior associated with the occupants' characteristics were the following:

- Tenants exhibited a lower occupant exigency index regarding maintenance than their owner counterparts;

- The occupants' degree of exigency concerning maintenance increased with the occupants' ages;

- The willingness to pay for maintenance costs was generally very low;

- Occupants between 35 and 65 years old were the most willing to pay.

Survey data also exposed a gap between the facility manager's assessment of the occupants' expectations and their actual perception, which further highlights the factual value of this sort of systematic evaluation for supporting the facility manager in everyday decisions, as well as broader strategic maintenance planning.

These early results endorse the usefulness of the proposed POE method for BMPE. Further research might include:

- Evaluating a wider sample of buildings;

- Widening the range of ESMs surveyed;

- Applying the method to buildings with different uses;

- Adapting the method for the performance evaluation of maintenance teams.

Acknowledgments: The authors would like to acknowledge the involvement of the MSc student Diogo Almeida, who assisted on the production of a part of the questionnaires in the context of his MSc thesis.

Author Contributions: This study is the result of the research conducted by Nelson Bento Pereira on the Faculty of Engineering of the University of Porto and wide professional experience as CEO of a facilities management firm in the city of Porto, and was supervised by the colleagues Rui Calejo Rodrigues and Patrícia Fernandes Rocha, who provided critical judgment on the research being undertaken. The paper was written with the contribution of all authors.

Conflicts of Interest: The authors declare no conflict of interest.

\section{Abbreviations}

$\begin{array}{ll}\text { POE } & \text { post-occupancy evaluation } \\ \text { ESM } & \text { elements source of maintenance } \\ \text { BMPE } & \text { building maintenance performance evaluation } \\ \text { CV } & \text { coefficient of variation } \\ \text { OEI } & \text { occupant exigency index }\end{array}$




\section{References}

1. EN15643-4:2012 Sustainability of Construction Works-Assessment of Buildings_Part 4: Framework for the Assessment of Economic Performance; European Committee for Standardization: Brussels, Belgium, 2012.

2. Zimring, C.M.; Reizenstein, J.E. Post-occupancy evaluation: An overview. Environ. Behav. 1980, 12, 429-450. [CrossRef]

3. Zimmerman, A.; Martin, M. Post-occupancy evaluation: Benefits and barriers. Build. Res. Inf. 2001, 29, 168-174. [CrossRef]

4. Leaman, A.; Stevenson, F.; Bordass, B. Building evaluation: Practice and principles. Build. Res. Inf. 2010, 38, 564-577. [CrossRef]

5. Preiser, W.F.E. Post-occupancy evaluation: How to make buildings work better. Facilities 1995, 13, $19-28$. [CrossRef]

6. Council, Federal Facilities. Learning from Our Buildings: A State-of-the-Practice Summary of Post-Occupancy Evaluation; National Academy Press: Washington, DC, USA, 2001.

7. Wongbumru, T.; Dewancker, B. Post-occupancy evaluation of user satisfaction: A case study of 'old' and 'new' public housing schemes in Bangkok. Archit. Eng. Des. Manag. 2016, 12, 107-124. [CrossRef]

8. Adekunle, T.O.; Nikolopoulou, M. Thermal comfort, summertime temperatures and overheating in prefabricated timber housing. Build. Environ. 2016, 103, 21-35. [CrossRef]

9. Seeley, H. Building Maintenance; Macmillan Press Ltd.: London, UK, 1976.

10. ISO6707-1:2014 Buildings and Civil Engineering Works_Vocabulary_Part 1: General Terms; International Organization for Standardization: Brussels, Belgium, 2014.

11. Rodrigues, R.C.; Rocha, P.F. Importance of building maintenance at the time of architectural design of buildings rehabilitated with heritage value. J. Xi'an Univ. Archit. Technol. 2011, 43, 768-776.

12. Schwarz, N.; Hippler, H.J. Response alternatives: The impact of their choice and presentation order. In Measurement Error in Surveys; Biemer, P.P., Groves, R.M., Lyberg, L.E., Mathiowetz, N.A., Sudman, S., Eds.; Wiley: New York, NY, USA, 1991; pp. 41-56.

(C) 2016 by the authors; licensee MDPI, Basel, Switzerland. This article is an open access article distributed under the terms and conditions of the Creative Commons Attribution (CC-BY) license (http://creativecommons.org/licenses/by/4.0/). 